\title{
Corpus - possibilidade metodológica para o ensino da variação linguística na aula de PLNM
}

\author{
Carla Sofia Araújo \\ Instituto Politécnico de Bragança - Escola Superior de Educação, Portugal \\ Centro de Estudos em Letras, Universidade de Trás-os-Montes e Alto Douro, Portugal
}

\section{Resumo}

As diferenças entre o português europeu e o português brasileiro observamse nos diversos módulos da gramática da Língua Portuguesa. Uma vez que o léxico é a parte da gramática que mais absorve os condicionamentos sociohistóricos e culturais, é no léxico que se constatam maiores divergências, ainda que o português europeu e o português brasileiro partilhem um fundo lexical comum. Graças a essa partilha lexical, opera-se uma comunicação eficaz entre falantes do português europeu e falantes do português brasileiro, embora os usos discursivos, convencionais e pragmáticos na interação linguística no Brasil e em Portugal sejam distintos. Na sequência das especificidades da Língua Portuguesa anteriormente referidas, colocam-se duas questões essenciais, a que procuraremos dar resposta com este trabalho: tendo em vista o ensino da diversidade linguística na aula de PLNM, que visão da língua deve apresentar o Professor de PLNM? No ensino da diversidade linguística na aula de PLNM, o "Corpus do Português”, disponível online em www.corpusdoportugues.org., poderá ser um recurso didático profícuo?

Palavras-chave: Corpus, variação linguística, ensino do PLNM.

\section{Introdução}

O trabalho que agora se apresenta pretende expor uma possibilidade metodológica para o ensino da variação linguística na aula de PLNM através de corpus. Nesse sentido, começase por apresentar evidências a propósito das diferenças entre o português europeu (PE) e o português brasileiro (PB), depois, no escopo da variação linguística e o ensino do PLNM, preconiza-se uma visão contrastiva português europeu/português brasileiro mediada pelo uso de corpora, destacando o "Corpus do Português", de Mark Davies, e termina-se com a 
apresentação de uma proposta didática para o estudo das variedades do português faladas em Portugal e no Brasil, no nível lexical, através da observação e análise de concordâncias no "Corpus do Português".

\section{Uma Língua com duas variedades nacionais: Português Europeu e Português Brasileiro}

A variação é uma característica intrínseca de qualquer língua, podendo observar-se quer no passado quer no presente e manifesta-se como diversidade dialetal ou sociolinguística (Segura 2013). O português europeu foi levado para as novas terras descobertas no início do século XVI, entrando em contacto com as diversas línguas indígenas brasileiras, as diversas línguas africanas dos falantes envolvidos no tráfico negreiro e as múltiplas línguas europeias e asiáticas dos emigrantes que chegaram ao Brasil, a partir de meados do século XIX. Segundo Silva (2013), este contacto entre falantes de línguas distintas "foi configurando, através de uma história longa e complexa, o que é atualmente a variedade brasileira da língua portuguesa: o português do Brasil, hoje falado por mais de cento e setenta milhões de pessoas." (p. 145).

Os dados históricos demonstram que a maioria dos brasileiros adquiriu o português europeu, língua do colonizador e língua do poder e do prestígio social, por um "processo de transmissão irregular, favorecedora de uma aquisição imperfeita; [...] era adquirido na oralidade do quotidiano e, dada a escolarização praticamente inexistente, na ausência de uma normativização que só poderia ser veiculada pelo ensino" (Silva, 2013, pp. 147-148).

A investigação tem reunido evidências a propósito das diferenças entre o PE e o PB, vejase, entre outros, Teyssier (1982, p. 78-88), Mattos e Silva (2004, p. 140-147), Castilho (2010, p. 171-195) e Silva (2014, p. 143-188).

Mateus (2003) apresenta exemplos de algumas das diferenças do PE e do PB patentes quer nos níveis em que as divergências são mais percetíveis, ou seja, os níveis fonético, fonológico e lexical, quer nos níveis morfológico e sintático-semântico.

As diferenças entre o português europeu e o português brasileiro observam-se nos diversos módulos da gramática, no entanto, como se conclui em Mateus (2003), "a deriva das duas variedades utiliza processos gramaticais comuns, não podendo afirmar-se, portanto, que as variedades do português possuem diferentes gramáticas" (p. 51).

Uma vez que o léxico é a parte da gramática que mais absorve os condicionamentos sociohistóricos e culturais, é no léxico que se constatam maiores divergências, ainda que o português europeu e o português brasileiro partilhem um fundo lexical comum. Graças a 
essa partilha lexical, opera-se uma comunicação eficaz entre falantes do português europeu e falantes do português brasileiro, embora os usos discursivos, convencionais e pragmáticos na interação linguística no Brasil e em Portugal sejam distintos.

Na sequência das especificidades da Língua Portuguesa anteriormente referidas, colocamse duas questões essenciais, a que procuraremos dar resposta nas secções seguintes: tendo em vista o ensino da diversidade linguística na aula de PLNM, que visão da língua deve apresentar o Professor de PLNM? No ensino da diversidade linguística na aula de PLNM, as ferramentas TIC poderão ser um recurso didático profícuo?

\section{Variação linguística e ensino do PLNM}

Efetivamente, a variação é uma característica intrínseca de qualquer língua, podendo observar-se quer no passado quer no presente. Sendo o português uma língua pluricêntrica (Silva 2014), ou seja, uma língua que possui diversas variedades e que duas delas, o português europeu e o português brasileiro, se encontram normalizadas, isto é, possuem normas padrão reconhecidas e descritas linguisticamente, em contexto de ensinoaprendizagem, o professor de PLNM deve apresentar uma visão contrastiva PB/PE (Duarte 2016), quer nos níveis de proficiência iniciais quer nos níveis avançados, em conformidade com o Quadro Europeu Comum de Referência para as línguas (QECR).

De acordo com Ellis \& Shintani (2014, p. 26), nos objetivos do ensino da língua, não cabe apenas o desenvolvimento da competência comunicativa dos estudantes, deve caber também a promoção do saber ser e do saber estar no mundo, que permita aos alunos a reflexão crítica sobre os valores, as atitudes e crenças.

A aula de variação linguística deve favorecer essa competência existencial, facilitando "o desenvolvimento de "uma personalidade intercultural"”" (Conselho da Europa, 2001, p. 153), que, inquestionavelmente, configura um fim educativo relevante.

A investigação tem revelado que o uso de corpus na sala de aula de línguas configura um contexto pedagógico-didático favorável à aprendizagem autónoma, exercendo um impacto especial na aquisição lexical (McCullough, 2001).

É importante realçar o corpus como ativador do papel do aluno no processo de aprendizagem da língua, isto é, o corpus constitui-se como um campo fértil para estimular a curiosidade do aluno, levando-o a fazer explorações e descobertas linguísticas (Sardinha 2011; 2016; 2017). 
Com efeito, o enfoque indutivo subjacente à utilização de corpus na sala de aula sustenta que a observação dos dados linguísticos conduz o aluno a extrair as regras e os princípios gerais que regulam a língua. Tal como argumenta St. John,

using corpora and a concordancer can be motivating and rewarding not only for the learner but also for the teacher. For the teacher, these tools can provide contextualised examples to confounding lexical questions. Moreover, the learner can develop an ability to "learn how to learn" [...] This therefore assists the student in exploring the language in great detail and thereby gaining further insights into its grammar and vocabulary (St. John, 2001, p. 185).

Como recorda Mendes (2016), o uso de corpora é alvo de interesse por diversos domínios de estudos da língua. Nesse sentido, Mendes (2016, p. 224-251) problematiza a conceção de corpus quer como fonte de dados linguísticos quer como método de trabalho em estudos linguísticos que se ancoram em teorias linguísticas diversas. Além disso, a autora apresenta também uma lista com os endereços web de vários tipos de corpora disponíveis para o Português (Mendes, 2016, p. 244-247): corpora de fala, corpora de português não contemporâneo, corpora de variedades regionais de PE, corpora de variedades do português no mundo, corpora paralelos, corpora de aquisição e corpora de aprendizagem.

Efetivamente, na Web, deparamo-nos com bases diversificadas que divulgam e disponibilizam corpora que poderão ser recursos importantíssimos para o ensino da diversidade linguística na aula de PLNM. No âmbito dessas bases, começamos por destacar o "Corpus do Português", que iremos utilizar na secção seguinte deste trabalho. Podemos encontrá-lo disponível em https://www.corpusdoportugues.org/web-dial/. Destaca-se também a Linguateca, que é um centro de recursos para o processamento computacional da língua portuguesa, onde se encontra disponível o "corpus CONDIVport", em http://www.linguateca.pt/acesso/corpus.php?corpus=CONDIV. Os textos deste corpus pertencem aos domínios do futebol, do vestuário/moda e da saúde das décadas de 50, 70 e 2000 de jornais e revistas portugueses, tendo sido criado com o objetivo de estudar a "CONvergência" e a "DIVergência" entre estas duas variantes do português.

Destaca-se de igual modo a base de dados do Instituto de Linguística Teórica e Computacional (ILTEC), resultante do projeto LUPo (Léxico Unisyn do Português), o RADbank (Regional Accent Databank), acessível em http://radbank.iltec.pt/ (O RADbank pode ser consultado através da página do Portal da Língua Portuguesa (www.portaldalinguaportuguesa.org), clicando em "RADbank" do lado direito do menu "Consultar".). Os utilizadores deste recurso podem selecionar um país da CPLP. Ao selecionar "país", será apresentada ao utilizador da ferramenta a opção de pesquisar por informante ou por variedade regional (http://radbank.iltec.pt/index.php?action=countries; http://radbank.iltec.pt/index.php?action=words). 
De facto, na Web, facilmente podemos aceder a uma panóplia diversificada de corpus. Não obstante, “o que vemos é uma escassez de materiais de ensino de língua materna e estrangeira baseados em corpora em todos os níveis." (Sardinha, Delfino \& Rampaso, 2017, p. 2), ainda que a investigação recente nos dê conta das potencialidades da utilização de corpus em sala de aula (Piñol, 2016; Finatto et al., 2018).

Por conseguinte, a incorporação de corpus em sala de aula representa um poderoso instrumento ao serviço do desenvolvimento da competência lexical dos alunos que se encontram em situação de aprendizagem de uma língua estrangeira (Piñol, 2016).

De acordo com o QECR, a competência lexical traduz-se "no conhecimento e na capacidade de utilizar o vocabulário de uma língua e compreende elementos lexicais e gramaticais" (Conselho da Europa, 2001, p. 159). Na secção seguinte, apresenta-se uma proposta didática de estudo da variação linguística através do "Corpus do Português", que constitui uma possibilidade metodológica ao serviço do desenvolvimento da competência lexical dos estudantes de PLNM.

\section{Proposta didática de estudo da variação linguística através do "Corpus do Português"}

Tendo em vista o ensino-aprendizagem das variedades do português faladas em Portugal (PE) e no Brasil (PB), no nível lexical (Mateus, 2003, p. 50-51), o professor poderá apresentar aos estudantes alguns exemplos como os que se apresentam nos quadros a seguir.

Quadro 1. Palavras idênticas com significado diferente

\begin{tabular}{|c|c|c|c|}
\hline \multicolumn{4}{|c|}{ Divergências - Palavras idênticas com significado diferente } \\
\hline \multirow{5}{*}{$\begin{array}{l}\text { Nível } \\
\text { Lexical }\end{array}$} & & PE & PB \\
\hline & & & \\
\hline & apelido & Sobrenome & alcunha \\
\hline & banheiro & salva-vidas & casa de banho \\
\hline & camisola & t-shirt, blusa & camisa de dormi \\
\hline
\end{tabular}


Quadro 2. Palavras diferentes com o mesmo significado

\begin{tabular}{|l|l|l|}
\hline \multicolumn{3}{|c|}{ Divergências - Palavras diferentes com o mesmo significado } \\
\hline \multirow{4}{*}{$\begin{array}{l}\text { Nível } \\
\text { Lexical }\end{array}$} & \multicolumn{1}{|c|}{ PE } & \multicolumn{1}{c|}{ PB } \\
\cline { 2 - 3 } & Cunha & pistolão \\
\cline { 2 - 3 } & Adesivo & esparadrapo \\
\cline { 2 - 3 } & Betão & concreto \\
\hline
\end{tabular}

Quadro 3. Palavras derivadas com a mesma base e diferentes sufixos mas com significado semelhante

\begin{tabular}{|l|l|l|}
\hline \multicolumn{2}{|c|}{$\begin{array}{r}\text { Divergências - Palavras derivadas com a mesma base e diferentes sufixos mas } \\
\text { com significado semelhante }\end{array}$} \\
\hline \multirow{4}{*}{$\begin{array}{l}\text { Nível } \\
\text { Lexical }\end{array}$} & PE & \multicolumn{1}{c|}{ PB } \\
\cline { 2 - 3 } & fumador & fumante \\
\cline { 2 - 3 } & prestável & prestativo \\
\hline
\end{tabular}

Quadro 4. Palavras com bases diferentes e com o mesmo sufixo, mas que veiculam um significado idêntico

\begin{tabular}{|l|l|l|}
\hline \multicolumn{2}{|c|}{$\begin{array}{c}\text { Divergências - Palavras com bases diferentes e com o mesmo sufixo, mas que } \\
\text { veiculam um significado idêntico }\end{array}$} \\
\hline \multirow{3}{*}{$\begin{array}{l}\text { Nível } \\
\text { Lexical }\end{array}$} & PE & \multicolumn{1}{c|}{ PB } \\
\cline { 2 - 3 } & carnudo & polpudo \\
\cline { 2 - 3 } & canalizador & encanador \\
\hline
\end{tabular}

Apresentadas algumas variedades do português faladas em Portugal (PE) e no Brasil (PB), particularmente no nível lexical (palavras idênticas com significado diferente; palavras diferentes com o mesmo significado; palavras derivadas com a mesma base e diferentes sufixos mas com significado semelhante; palavras com bases diferentes e com o mesmo sufixo, mas que veiculam um significado idêntico), o professor poderá propor aos alunos de PLNM, a partir do nível B1, a extração de concordâncias no "Corpus do Português" (Davies 2018). Este corpus, criado por Mark Davies, possui cerca de um bilhão de palavras em Português, retiradas de aproximadamente um milhão de páginas web de quatro países lusófonos (Brasil, Portugal, Angola e Mocambique).

Deste modo, a utilização deste corpus, através da observação e análise das concordâncias das formas linguísticas do PE e do PB, como se ilustra nas figuras 1 e 2, permitirá a exemplificação das referidas variações linguísticas, confrontando os alunos com a multiplicidade das variações dos usos da língua portuguesa, não se limitando ao 
conhecimento dos usos linguísticos que o professor possui, que é inevitavelmente fragmentário.

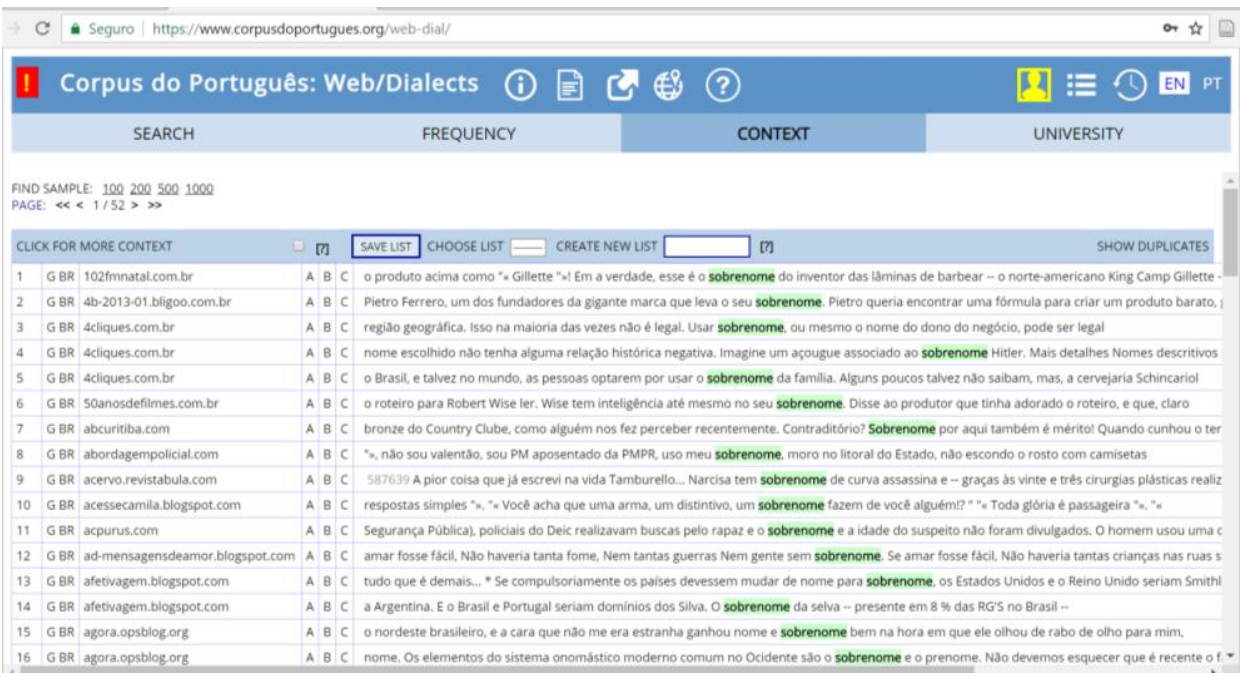

Figura 1 Concordâncias de "sobrenome"

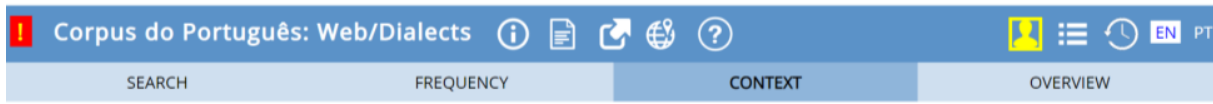

FIND SAMPLE: 1002005001000

PAGE: $\ll<1 / 26 \gg \gg$

\begin{tabular}{|c|c|c|c|c|c|}
\hline & KFOR N & MORE CONTEXT & & & SHOW DUPLICATES \\
\hline 1 & GBR & 180graus.com & A $B$ & & se destaca fisicamente em relaç̧o aos outros profissionais de arbitragem, mas dispensa a alcunha de 'forţ̊o' e alerta: "w eu quero ser conhecido po. \\
\hline 2 & $G B R$ & a.partir-pedrablogspot.com & & $8 \mathrm{c}$ & ou do Estado de Săo Paulo) e eu catarinense (ou barriga-verde, alcunha dos nascidos em este maravilhoso Estado de Santa Catarina). Caro Rui, \\
\hline 3 & GBR & acertodecontas.blog.br & A & $\mathrm{B} \mathrm{c}$ & Em um pais onde existe um tal de Paulo maluf, outro com a alcunha de juiz lalau etc. ter o nome no serasa nåo é motivo de \\
\hline 5 & GBR & acervo.revistabula.com & A & B c & enganaçōes de Maria da Anunciaçăo - a iletrada (e desletrada) Emanuele - cuja alcunha foi a ela imposta, ainda nos primórdios da prostituiçăo na cic \\
\hline 6 & GBR & acervo.revistabula.com & A & $8 \mathrm{c}$ & 1. Léo assume que nåo gosta dos negros, embora nåo aceite a alcunha de racista (7). Foi ao cinema, única e exclusivamente \\
\hline 7 & GBR & acervo.revistabula.com & A & B C & que pouquissimo amo e amei, além de nå ser diabético, ainda considero a alcunha deveras ridicula, além de hipercalórica. De a mesma forma, "* mi \\
\hline 10 & GBR & afinsophia.com & A $B$ & $\mathrm{BC}$ & se chama Manuel Mateus, mas nào é parente de Sete-Sois, e tem por alcunha Saramago, sabe- se lă que descendéncia a sua serd, e que saiu penitent \\
\hline 11 & GBR & albertomurray.wordpress.com & A & $\mathrm{BC}$ & Copa do Mundo, querem demonizar os criticos e colar- thes sobre as testas a alcunha de anti-brasileiros. Reparem como as portas da Copa das Confe \\
\hline 12 & GBR & amaivos,ual.com.br & A 1 & B C & de Beauchamp e Childress, conhecida nos anos posteriores de sua publicaça pela alcunha de bioética principialista, discutia as questoes morais sob \\
\hline 13 & GBR & aorigemdosproverbios.blogspot.com & A 8 & B C & mundo. Se ele nåo se envergonhava de isso, o pior era mesmo a alcunha que tinha pela aldeia, e para a qual muito contribuiam os dois factores \\
\hline 14 & GBR & arautodofuturo.wordpress.com & A & $\mathrm{BC}$ & Universidade indiana e retomou uma atvidade: a de "* cientista cantora "w, A alcunha surgiu quando jill iniciou uma campanha em prol da doaçăo de \\
\hline
\end{tabular}

Figura 2 Concordâncias de "alcunha" 


\section{Considerações finais}

As opções didáticas através de corpus rentabilizam as potencialidades que a Linguística de Corpus concede ao ensino das línguas.

De facto, os corpus que os recursos tecnológicos nos disponibilizam configuram uma possibilidade metodológica que permite aos professores e alunos desbravar novos horizontes no ensino-aprendizagem da variação linguística na aula de PLNM. Deste modo, no ensino da diversidade linguística na aula de PLNM, o "Corpus do Português", disponível online em www.corpusdoportugues.org., poderá ser um recurso didático prolífero, uma vez que concede aos alunos a possibilidade de observar e analisar a multiplicidade das variações dos usos da língua portuguesa e permite aos professores orientar os alunos de PLNM para a descoberta dos contrastes existentes entre o português europeu e o português brasileiro.

Nesta linha de pensamento, concluímos com as palavras de Tagnin (2018), dado que consideramos que o ensino tem muitíssimo "a ganhar em termos de objetividade e confiabilidade com o uso da Linguística de Corpus, principalmente porque a tecnologia avança a passos largos nesse setor, permitindo a criação de ferramentas que permitem análises cada vez mais específicas e direcionadas.” (p. 14).

\section{Referências}

Castilho, A. (2010). Nova Gramática do Português Brasileiro. São Paulo: Editora Contexto.

Conselho da Europa (2001). Quadro europeu comum de referência para as línguas: aprendizagem, ensino, avaliação. Porto: Asa. Disponível para descarregar em www.dgidc.minedu.pt/.../data/.../quadro_europeu_comum_referencia.pdf

Davies, M. (2018). Corpus do Português. http://www.corpusdoportugues.org> (Acedido em $12 / 06 / 2019)$

Duarte, I. M. (2016). "Português, Língua Pluricêntrica: Que Português Ensinar Em Aulas De Língua Estrangeira?”. In: C. B. Andrade; G. Micheletti; I. Seara (Org). Memória Discurso E Tecnologia. São Paulo: Terracota Editora, 217-236.

Ellis, R. \& Shintani, N. (2014). Exploring Language Pedagogy through Second Language Acquisition. Londres: Routledge.

Finatto, M. J. B., Rebechi, R. R., Sarmento, S. \& Bocorny, A. E. P. (2018). Linguística de corpus: perspectivas. Porto Alegre: Instituto de Letras - UFRGS, pp. 11-14. Disponível em http://www.revistadiadorim.letras.ufrj.br/index.php/revistadiadorim/article/viewFile/362/318 
Mateus, M. H. M. (2003). "Dialetos e variedades do português”. In: Mateus, M. H. M., Brito, A. M., Duarte, I., Faria, I. H. et al. (2003). Gramática da Língua Portuguesa. Lisboa: Caminho, p. 45-51.

Mattos e Silva, R. V. (2004). Ensaios para uma Sócio-História do Português Brasileiro. São Paulo. Parábola Editorial, p. 140-147.

McCullough, J. L. (2001). "Los usos de los córpora de textos en la enseñanza de lenguas”. In: Parera, T. M (ed.): Nuevas tecnologías para el autoaprendizaje y la didáctica de lenguas. Lleida. Milenio, pp. 25-140.

Mendes, A. (2016). "Linguística de corpus e outros usos dos corpora em linguística". In: Ana Maria Martins e Ernestina Carrilho (eds.). Manual de linguística portuguesa. Berlin/Boston: De Gruyter, p. 224-251.

Piñol, M. C. (2016). “Léxico y ELE: enseñanza/aprendizaje con tecnologías”. Journal of Spanish Language Teaching, 2:2, 165-179.

Sardinha, T. B. (2011). "Como usar a Linguística de Corpus no Ensino de Língua Estrangeira”. In: VIANA, V. \& TAGNIN, S.E.O. Corpora no Ensino de Línguas Estrangeiras. São Paulo: HUB Editorial.

Sardinha, T. B. (2016). “Corpus-based teaching in LSP”. In: MARTIN-MONJE, E. et al. (Orgs.). Technology-enhanced language learning for specialized domains. Oxon: Routledge, pp. 203-315.

Sardinha, T. B., Delfino, M. C. \& Rampaso, M. (2017). "Preparação de material didático para ensino de línguas com base em corpora". In: The ESPecialist: Descrição, Ensino e Aprendizagem, Vol. 38, pp. 1-14. Disponível em https://revistas.pucsp.br/index.php/esp/article/view/32224.

Segura, L. (2013). "Variedades dialetais do português europeu". In: Raposo, E. (Org.) (2013). Gramática do português. Lisboa: Fundação Calouste Gulbenkian, pp. 85-142.

Silva, A. S. (2014). "The pluricentricity of Portuguese: A sociolectometrical approach to divergence between European and Brazilian Portuguese". In: Augusto Soares da Silva (ed.), Pluricentricity: Language Variation and Sociocognitive Dimensions. Berlin \& New York: Mouton de Gruyter, p. 143-188.

Silva, R. V. M. (2013). “O Português do Brasil”. In: Raposo, E. (Org.) (2013). Gramática do português. Lisboa: Fundação Calouste Gulbenkian, pp. 145-153.

St. John, E. (2001). "A case for using a parallel corpus and concordancer for beginners of a foreign language". In: Language Learning \& Technology, 5 (3), pp. 185-203. Disponível em http://llt.msu.edu/vol5num3/stjohn/

Tagnin, S. (2018). "E a Linguística de Corpus vai desbravando novos horizontes...". In: https://www.ufrgs.br/ppgletras/ebooks/2018Linguisticadecorpus_NOVO_FINAL.pdf

Teyssier, P. (1982). História da Língua Portuguesa. Lisboa: Livraria Sá da Costa Editora, p. 78-88. 